\title{
Generating probabilistic estimates of hydrological response for Irish catchments using a weather generator and probabilistic climate change scenarios
}

\author{
Satish Bastola, ${ }^{1 *}$ Conor Murphy ${ }^{1}$ and Rowan Fealy ${ }^{2}$ \\ ${ }^{1}$ ICARUS, Department of Geography, National University of Ireland, Maynooth, Ireland \\ ${ }^{2}$ Department of Geography, National University of Ireland, Maynooth, Ireland
}

\begin{abstract}
:
In accounting for uncertainties in future simulations of hydrological response of a catchment, two approaches have come to the fore: deterministic scenario-based approaches and stochastic probabilistic approaches. As scenario-based approaches result in a wide range of outcomes, the role of probabilistic-based estimates of climate change impacts for policy formulation has been increasingly advocated by researchers and policy makers. This study evaluates the impact of climate change on seasonal river flows by propagating daily climate time series, derived from probabilistic-based climate scenarios using a weather generator (WGEN), through a set of conceptual hydrological models. Probabilistic scenarios are generated using two different techniques. The first technique used probabilistic climate scenarios developed from statistically downscaled scenarios for Ireland, hereafter called SDprob. The second technique used output from 17 global climate models (GCMs), all of which participated in CMIP3, to generate change factors (hereafter called $C F$ ). Outputs from both the SDprob and the CF approach were then used in combination with WGEN to generate daily climate scenarios for use in the hydrological models. The range of simulated flow derived with the CF method is in general larger than those estimated with the SDprob method in winter and vice versa because of the strong seasonality in the precipitation signal for the $17 \mathrm{GCMs}$. Despite this, the simulated probability density function of seasonal mean streamflow estimated with both methods is similar. This indicates the usefulness of the SDprob or probabilistic approach derived from regional scenarios compared with the CF method that relies on sampling a diversity of response from the GCMs. Irrespective of technique used, the probability density functions of seasonal mean flow produced for four selected basins is wide indicating considerable modelling uncertainties. Such a finding has important implications for developing adaptation strategies at the catchment level in Ireland. Copyright @ 2011 John Wiley \& Sons, Ltd.
\end{abstract}

KEY WORDS probabilistic climate change scenario; hydrological models; weather generators; Generalised Likelihood Uncertainty Estimation (GLUE)

Received 24 February 2011; Accepted 23 September 2011

\section{INTRODUCTION}

Global climate models (GCMs), representing dynamic simulations of natural climatic processes, are the most widely used tools for modelling future climate. However, our limited understanding of the many components of the climate system (e.g. cloud feedbacks) and their role in climate change impose limitations on our ability to reliably simulate the future climate using GCMs, resulting in significant uncertainties being associated with future simulations. Despite these uncertainties, top-down approaches to impact assessment has been widely used in the international and grey literature with only limited success in aiding the development of adaptation decisions due to the associated wide range of outcomes (Wilby and Dessai, 2010). When confronted with uncertainty, defining an optimum approach in providing information for developing policy has been, and continues to be, a major source of contention and debate. A popular way of

*Correspondence to: Satish Bastola, ICARUS, Department of Geography, National University of Ireland, Maynooth, Ireland. E-mail: satish. bastola@nuim.ie estimating a best guess climate projection is to take a mean value estimated from a multimodel ensemble of climate projection (Knutti et al., 2010). An alternative to this is to use performance-based weighting (e.g. Giorgi and Mearns, 2003; Tebaldi et al., 2005), a subjective approach, although Grubler and Nakicenovic (2001) argued that we should research all the potential outcomes and not try to guess which is more likely to occur.

Assigning relevant uncertainty estimates requires using several models, running these models with different initial conditions, different model parameterisations, parameters and structures. Although a robust assessment of uncertainty requires the construction of projected ranges from a large number of emission scenarios and models, this is a key limiting factor in many situations. For example, because of constraints in computational resources, many global simulations are only available for a limited number of emissions scenarios.

Projected ranges can be constructed from the existing atmosphere-ocean global circulation models that participated in CMIP3 (the details of data and model can be found in Meehl et al., 2007) (e.g. Giorgi and Mearns, 2003; Greene et al., 2006; Min et al., 2007). However, 
they do not cover the full range of uncertainty in climate sensitivity. Alternatively, another approach that has been used in quantifying such uncertainties is based on exploring modelling uncertainties of a single GCM by sampling uncertain parameters from its prior distribution (e.g. Murphy et al., 2004; Stainforth et al., 2005). In a step towards realising a probabilistic climate prediction system, Stainforth et al. (2005) used a super-ensemble exploring uncertainty in a single GCM using a perturbed physics ensemble, constructed using plausible, but varying, sets of model parameters.

Apart from the uncertainty in emission scenario and climate model selection, uncertainties arising from downscaling method, hydrological model structure, parameters and observations also become relevant when climate projections are to be used in water resource applications (Wilby and Harris, 2006). Generally, although GCM output reproduces global and continental scale climate reasonably well, they are inadequate for use in impact studies because of differences in the scale at which GCMs provide output and the scale at which impacts are usually assessed (Wilby and Wigley, 1997). In recent decades, several methods have been used, particularly empirical/statistical downscaling and increasingly dynamical regional climate models (RCMs), to meet the need for high spatial and temporal resolution climate scenarios for use in impact studies (for a comprehensive review, see Fowler et al., 2007; Maraun et al., 2010). Many methods for the disaggregation of large-scale climate projections for hydrological impacts have emerged in the scientific literature. In particular, the work of Maraun et al. (2010) assessed the current downscaling literature, examining new developments in the field specifically for hydrological impacts.

The ability of RCMs to reproduce the present-day climate has improved significantly. However, the use of output from RCMs is often limited by systematic errors in the boundary conditions provided by both reanalysis data (Mooney et al., 2010) and GCMs, representing an additional contribution to the overall chain of uncertainty. Despite the benefits of statistical downscaling approaches in terms of simplicity of application, the use of regression-based procedures is limited to locations where good predictor-predictand relationships can be derived and require long observational data sets. Both techniques also require an assumption of time invariance with the transfer functions in statistical downscaling and parameterisation schemes in the RCMs. Alternatively, synthetic or statistical methods can also be used as a tool to develop future climate scenarios on the basis of GCM-simulated or subjectively introduced delta changes in climate for impact models (e.g. Wilks, 1992; Semenov and Barrow, 1997), and although not assumption free, they do provide a viable alternative to producing climate scenarios.

There are also several stochastic models for generating synthetic climatic data (e.g. Richardson and Wright, 1984; Racsko et al., 1991). These models generate one or more climatic variables from an existing set of data. A review on the use of weather generation models can be found in Wilks and Wilby (1999). A stochastic weather generator also allows temporal extrapolation of observed weather data for risk assessment as well as in providing an expanded spatial source of weather data by interpolation between the point-based parameters used to define the weather generators (Hutchinson, 1991). Apart from the generation of long time series, they also allow for the simulation of multiple realisations, thereby providing for wide ranges. The approaches based on stochastic weather generators are relatively simple, making them feasible for modelling multiple variables. They can also serve as a computationally inexpensive tool for producing site specific climate change scenarios at a more local scales.

Impact models are also inherently imperfect because they abstract and simplify real processes that are themselves imperfectly known and understood (Gupta et al., 2003). Experiences with the calibration of hydrological models suggest that their parameters are uncertain. Several studies have evaluated the impact of climate change and associated uncertainties at the catchment scale (e.g. Horton et al., 2006; Cameron, 2006; New et al., 2007; Cloke et al., 2010). Most of these impact studies have propagated the uncertainty in climate scenarios through a single hydrological model. New et al. (2007) examined the challenges of using probabilistic climate change information in impact studies in the water sector and showed that a probabilistic approach provides more informative results that enables the potential risk of impacts to be quantified but are conditional upon the approach used for the analysis. Cameron (2006) suggested that there is a need to consider multiple climate change scenarios and account for model uncertainties when estimating the possible effects of climate change upon flood frequency. Similarly, Cloke et al. (2010) observed the significant influence of model parameter uncertainty under future climate as river flows become lower. Although some studies have sought to address issues associated with parameter uncertainty (e.g. New et al., 2007; Cloke et al., 2010), very few have looked at the uncertainties related to model structure (e.g. Bastola et al., 2011), particularly in the context of climate change impact assessments.

From an Irish perspective, research on climate change impacts to date has been founded on the deterministic, scenario-based approach, using empirical statistical downscaling and RCMs to derive locally relevant climate scenarios that are then used to drive impacts models. More recently work has focussed on quantifying uncertainties in impacts, particularly in the area of catchment hydrology and water resources (e.g. Bastola et al., 2011; Hall and Murphy, 2010a, 2010b; SteeleDunne et al., 2008; Murphy and Charlton, 2008). Although this work has been effective in eliciting the bounds within which future impacts are likely to occur, their uptake by end users is likely to be slow because of the wide range of impacts simulated. Moreover, the results of the scenario-based approach are sensitive to the choice of driving GCMs (as shown in Bastola et al., 2011). 
Therefore, in this study, probabilistic climate scenarios are used in combination with a stochastic weather generator to assess the uncertainty in hydrological impacts while also accounting for hydrological model uncertainty derived from the parameters and structure of the selected models. The probabilistic approach presented here is derived from the distribution of global temperature change and regional scenarios. Such an approach is likely to result in more robust climate change impact assessment than the traditional single scenario-based approaches, which are based on a small number of GCMs and scenarios and which do not explicitly cater for uncertainties. Subsequently, the probability density function (PDF) for streamflow is constructed. However, because of the many scientific and modelling uncertainties, the availability of different statistical estimation approaches and imprecise information, a unique probability distribution for streamflow is impossible. The work presented here builds on that of Bastola et al. (2011) for Ireland by using probabilistic climate change information and stochastically generating climate scenarios for simulating hydrologic impact. However, both studies use the same set of catchments, hydrological models and basin simulators, thus providing a basis for future intercomparisons.

The article is structured as follows: Section 2 briefly describes the study region and data used. Section 3 provides a brief review of methods for developing probabilistic climate scenarios and generating future climate scenarios using a stochastic weather generator. Results are outlined in Section 4.

\section{STUDY REGION AND DATA}

The area of focus for this study is the Republic of Ireland. The location of synoptic weather stations, the boundaries of the river catchments and the distribution of annual rainfall are illustrated in Figure 1. Rainfall varies considerably across Ireland, associated largely with orography, with moderate seasonal variation, whereas temperature displays more seasonal variation. The impact of climate change on water resources at the catchment scale is investigated using four catchments (see Figure 1), namely, the river Blackwater at Ballyduff $\left(2302 \mathrm{~km}^{2}\right)$, the river Suck at Bellagill $\left(1219 \mathrm{~km}^{2}\right)$, the Moy at Rahans $\left(1803 \mathrm{~km}^{2}\right)$ and the Boyne at Slane Castle $\left(2452 \mathrm{~km}^{2}\right)$. These four catchments were selected because they represent the relatively diverse hydrological responses of catchments located throughout the Republic of Ireland in terms of their runoff coefficients and average rainfall conditions.

Probabilistic climate scenarios were developed initially from statistically downscaled climate scenarios derived from three GCMs and two Special Report Emission Scenarios (SRES) emission scenarios, namely, the A2 and B2 emission scenarios. These scenarios were previously statistically downscaled for 14 synoptic weather stations (Figure 1) by Fealy and Sweeney $(2007,2008)$ and were used to characterise future climate evolution. These downscaled data sets are interchangeably referred to as

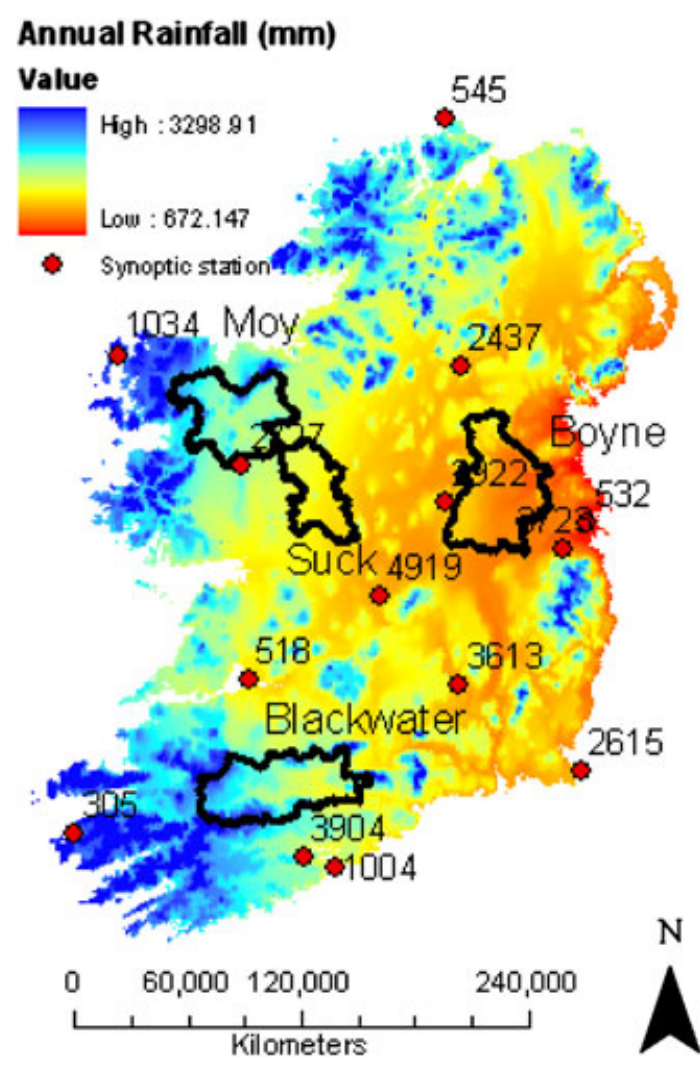

Figure 1. Synoptic stations, selected river catchments and spatial distribution of annual average rainfall

SDprob hereafter. The GCMs considered included HADCM3 from the Hadley Centre for Climate Prediction and Research (Met Office, UK), CGCM2 from the Canadian Centre for Climate Modelling and Analysis (CCCMA; Canada) and CSIRO-Mk2 from the Commonwealth Science and Industrial Research Organisation (CSIRO, Australia). The A2 and B2 scenarios represent future emissions levels that could be considered 'medium-high' (A2 emission) and 'medium-low' (B2 emission).

Probabilistic climate scenarios were also developed from direct output from 17 GCMs, referred to within this article as the change factor (CF) method. These GCMs (shown in Table I) represent the results of experiments from several international modelling centres that are currently available from the IPCC Data Distribution Centre (IPCC DDC) at http://www.ipcc-data.org. Each of the GCMs was run with the A1B, A2 and B1 SRES emission scenarios and comprise 51 future monthly climate scenarios (17 GCMs $\times 3$ SRES scenarios). As the spatial resolution of the GCMs used in this study varies, all GCMs were re-gridded to a common resolution $\left(3.75^{\circ} \times 3.75^{\circ}\right)$ before extraction. The $20 \mathrm{C} 3 \mathrm{M}$ run, which is an experiment that runs with greenhouse gases increasing as observed through the 20th century, is used as a control run.

Future potential evapotranspiration (PET) is not a direct output of the GCMs but is taken from Bastola et al. (2011), who estimated PET on the basis of present climate using the Hargreaves method, a radiation-based 
Table I. Name of the GCMs used for the construction of climate scenarios using the CF method

\begin{tabular}{llclcl}
\hline Scenario no. & Model (GCM) & Scenario no. & Model (GCM) & Scenario no. & Model (GCM) \\
\hline 1 & BCCR-BCM2.0 & 7 & ECHO-G & 13 & MIROC3.2 (Medres) \\
2 & CCSM3 & 8 & GFDL-CM2.0 & 14 & MRI-CGCM2.3.2 \\
3 & CGCM3.1 (T47) & 9 & GFDL-CM2.1 & 15 & PCM \\
4 & CNRM-CM3 & 10 & GISS-ER & 16 & UKMO-HadCM3 \\
5 & CSIRO-Mk3.0 & 11 & INM-CM3.0 & 17 & UKMO-HadGEM1 \\
6 & ECHAM5/MPI-OM & 12 & IPSL-CM4 & & \\
\hline
\end{tabular}

empirical model popularly used for the simulation of PET, for each of the GCMs. A generalised form of the Hargreaves method (Xu and Singh, 2000) that utilises solar radiation and temperature to compute PET is used. The solar radiation required by the Hargreaves method is estimated from maximum and minimum temperature, extraterrestrial radiation and coefficients (Hargreaves et al., 1985) for estimating solar radiation from temperature for Ireland (Supit, 1994). Observed stream flow data were obtained from the hydrometrics section of the Office of Public Works (available at http://www.opw. ie/hydro/), and observed precipitation and temperature data were obtained from Met Éireann, the Irish national meteorological service.

\section{METHODS}

The likely impact of climate change and the associated uncertainties in the hydrological response of the selected river basins are assessed through three steps. First, information on probabilistic estimates of future regional climate change for Ireland is obtained. Second, climatic time series were generated on the basis of the WGEN weather model and probabilistic climate scenarios, the parameters of which are calibrated on the basis of observed data and suitably modified to account for future changes in climate. Third, the generated synthetic time series of climate data are used to force four conceptual hydrological models. The schematic of the method is shown in Figure 2. The SDprob method used results from the statistically downscaled regional climate change scenarios from Fealy and Sweeney $(2007,2008)$ in conjunction with estimates of the transient climate response $\left(\Delta T 2 \times \mathrm{CO}_{2}\right)$, representing the likely distribution of global temperature at the time that atmospheric concentrations of $\mathrm{CO}_{2}$ reach double their preindustrial levels to generate probabilistic climate change scenarios as shown in Figure 2a (Fealy, 2010). This method is evaluated by comparing the derived probabilistic scenarios and hydrological response with outputs on the basis of the CF method estimated from the direct output of the GCMs (Figure 2b).

\section{Probabilistic climate scenarios}

Probabilistic climate projections derived from multiple GCMs and emissions combinations are likely to result in more robust estimates of change, assuming a large number of independent GCMs are used. For several reasons, the independence between GCMs is not easily definable. Edwards (2001) indicated that the development of many existing GCMs can be traced from a small number of GCMs used in the late 1970s. These GCMs (a)

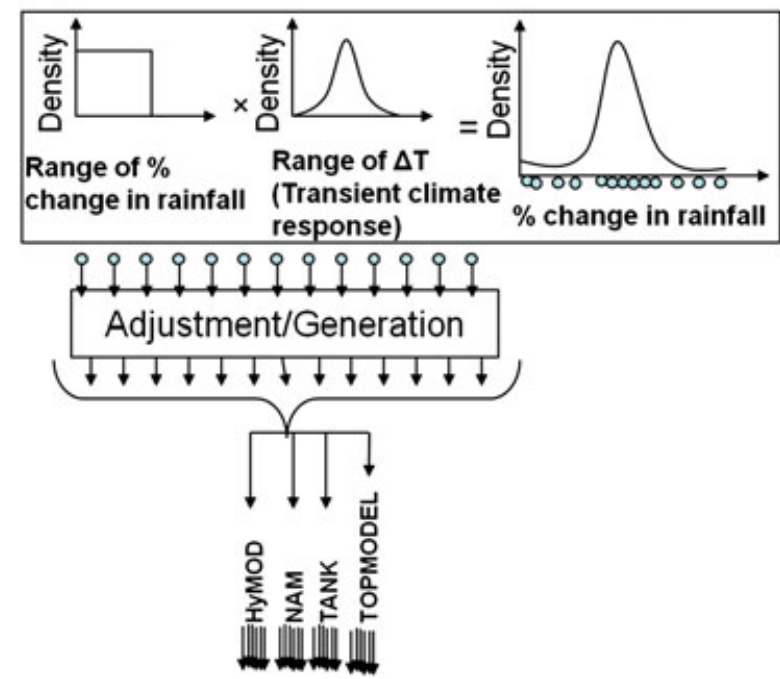

(b)

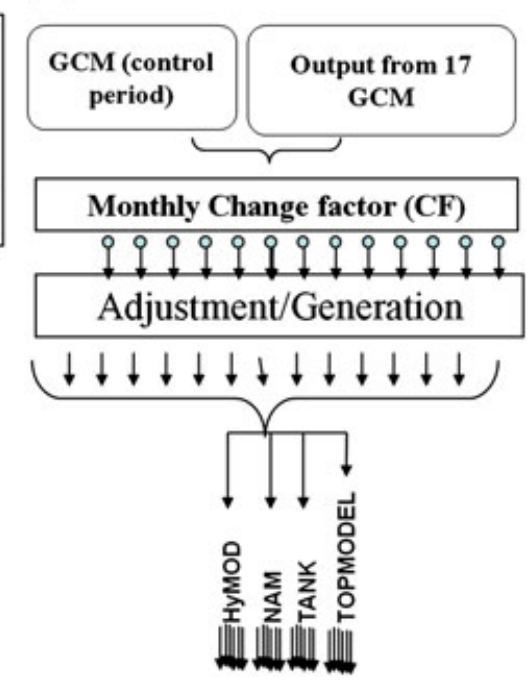

Figure 2. Schematic of the method used to account for modelling uncertainties in climate change impact studies by propagating climate scenarios through four hydrological models, namely, HyMOD, NAM, TANK and TOPMODEL. (a) Flow diagram for the estimation of probabilistic scenarios constructed from the distribution of global mean temperature and regional scenarios. (b) Flow diagram for probabilistic scenarios constructed from several GCMs 
often use the same set of physical equations, modelling strategies and observational data. However, the argument in favour of independency is that GCMs often use different parameterisations, initial conditions and sometimes take into account different physical phenomena. However, the use of output from different GCMs has been taken as a strategy for increasing the robustness in climate change impact studies. Such a strategy presents limiting factors in developing fully probabilistic regional scenarios, particularly due to the large computational and storage requirements for running multiple global-scale simulations. Consequently, climate modelling centres generally only undertake century-scale simulations for a restricted range of emissions scenarios, namely, the A2 and the B2 emission scenarios.

In response to the limited availability of particular GCM emission scenario combinations is pattern scaling (Santer et al., 1990), where the spatial and the climatic responses from a limited number of GCMs are scaled according to changes in global surface temperature (e.g. $\left.\Delta T 2 \times \mathrm{CO}_{2}\right)$. Pattern scaling provides a simple means in which regional responses can be rapidly calculated for alternative emissions scenarios. Although the approach assumes that the geographical or 'response' pattern of change remains constant and that the regional response is linearly related to the change in global mean surface temperature, the technique has found widespread application. The assumption of the local or regional climate being proportional to the global mean surface temperature seems to hold in many cases but is likely to be more robust for temperature than for precipitation (Mitchell et al., 1999; Mitchell, 2003; Murphy et al., 2004).

Development of probabilities from statistically downscaled data (SDprob). New and Hulme (2000) used a wide range of GCM output from several greenhouse gas emission scenarios, a range of climate sensitivities and the output from seven transient climate change simulations made using GCMs. The authors produced probability distributions for changes in seasonal mean temperature and precipitation over the United Kingdom using a hierarchical model in Bayesian Monte Carlo simulations. Fealy (2010) used a similar method to New and Hulme (2000) to produce probabilistic-based regional climate scenarios for Ireland on the basis of the statistically downscaled scenarios of Fealy and Sweeney (2007, 2008). This is the first time that pattern scaling has been applied to statistically downscaled scenarios, and the assumptions of independence of response pattern and regional response proportional to the global mean temperature were tested on the basis of the empirically downscaled A2 and B2 emissions scenario, which seemed valid. The subsequent work in this article is based on the probabilistic climate change scenario produced by Fealy (2010), which was developed to account for some of the key uncertainties associated with projected warming. The scenarios are defined as the estimates of future seasonal mean climate change for the period from 2070 to 2099 . A brief description of the methodology adopted by Fealy (2010) is outlined as follows:

1. Estimate the range of seasonal mean precipitation change (\%) for a future time period from two SRES scenarios (A2 and B2) using the statistically downscaled data. A modified pattern scaling approach was then used to scale the statistically downscaled A2 and B2 scenarios for each of the three GCMs to calculate changes for the A1FI and B1 emissions scenarios on the basis of the global temperature change for each GCM and emissions scenario.

2. The local or station climate response (change in temperature, $\Delta T$, and precipitation, $\Delta P$ ) per degree of global warming was then calculated for each GCM and emission scenario (A1FI, A2, B2 and B1) [i.e. $\Delta T_{\text {Station }}$ (2070-2099)/ $\Delta T_{\text {Global }}$ (2070-2099)]. These 'standardised' rates of change provided an upper and a lower value for each location, which were assumed to characterise a wide range of warming rates per degree Celsius. This step also allows for the removal of the effects of different GCM climate sensitivities.

3. The upper and the lower ranges estimated in step 2 were ascribed a uniform (equal-probability) distribution on the basis that it is not possible to determine 'more' or 'less' likely values for the local rate of warming.

4. The $5 \%-95 \%$ probability range $\left(1.5^{\circ} \mathrm{C}-2.8^{\circ} \mathrm{C}\right)$ of global $\Delta T$, estimated from the transient climate response and assuming a normal distribution (IPCC, 2007), was used to provide information on global $\Delta T$.

5. A Monte Carlo analysis was then used to randomly sample from (i) the range in global $\Delta T$ (step 4) and (ii) the local climate response in precipitation $(\Delta \mathrm{P})$ (steps 2 and 3) from their respective probability distribution.

The climate scenarios generated from previous procedure (Fealy, 2010) forms the basis for the construction of daily climate scenarios and subsequent evaluation of their role in climate change impact studies.

Development of CFs from direct GCM output (CF method). In addition to the SDprob approach, probabilistic climate change scenarios based on CFs derived from 17 GCMs (Table I), corresponding to the A2 SRES scenario, were also constructed. By calculating the CF from these outputs, probabilistic estimates of the monthly CFs are made. Contrary to the method based on Fealy (2010), CF method approach only calculates a CF for a single grid representing Ireland.

\section{Generation of climate time series}

There is now a large published literature on the strengths and weaknesses of different downscaling methods. Few, however, have evaluated the differences among various downscaling methods on the basis of their implications for hydrological predictions (e.g. Wilby et al., 2000). Because of the tradeoffs in the computational cost (the cost involved in using the regional climate change scenario obtained from 
RCM and statistical downscaling method for hydrological application) and the need to include a wide range of GCMs for fuller characterisation of uncertainties, this study opted to use a stochastic approach for the generation of climate scenarios for hydrological application. In the following sections, further detail is given to the application of each step in this process.

Weather generator. The weather generator model WGEN (Richardson and Wright, 1984) used in this study is a stochastic model that has been applied across wide geographic regions such as USA (e.g. Richardson and Wright, 1984), Europe and Asia (e.g. Semenov et al., 1998). WGEN uses a first-order Markov chain to determine whether a day is wet or dry by analysing historic precipitation records for each location and by using simple probability to define the wet or dry status of a given day. WGEN uses a two-parameter gamma distribution to synthesise the distribution of rainfall amounts. The two parameters, that is, shape $(\alpha)$ and scale $(\beta)$, for each location is determined from the observed records. Distributions with a low value of $\alpha$ are positively skewed and become more symmetrical with an increase in the value of $\alpha$. The scale parameter characterises the scale of intensity of the precipitation. A shape-dominated distribution (high-value shape factor) describes a pattern where rainfall tends to be symmetrically distributed and rainfall is consistent, and a scale-dominated distribution (high-value scale factor) describes locations where the variances are relatively higher than the mean.

The first-order two-state Markov model used in WGEN may fail to adequately model the time series of precipitation that display extended wet or dry spells because of low memory. Models such as WeaGETS (e.g. Caron et al., 2008), which use a higher-order Markov model, can provide a longer 'memory' to model data that has extended dry and wet spells. LARS-WG (Semenov and Barrow, 1997) can address this issue using a semi-empirical distribution of precipitation series. However, both WeaGETS and LARSWG are not as parsimonious as WGEN. In addition, the added complexity may offset the benefit brought by LARSWG and models with high memory, especially while making adjustment under future climate change scenarios.

Stochastically generated climate scenarios. When using the calibrated parameters of WGEN for generating scenarios, it is necessary to adapt them to generate time series that are consistent with assumed future climates. Wilks (1992) provided a method to adjust the calibrated parameters of WGEN to a changing climate. In this method, the monthly change in mean and variance of the selected variables between the simulated control and future is used.

$$
\begin{gathered}
\mu^{\prime} / \mu=\pi^{\prime} \alpha^{\prime} \beta^{\prime} / \pi \alpha \beta \\
\sigma^{\prime 2} / \sigma^{\prime 2}=\frac{\pi^{\prime} \alpha^{\prime} \beta^{\prime 2}\left[1+\alpha^{\prime}\left(1-\pi^{\prime}\right)\left(1+d^{\prime}\right) /\left(1-d^{\prime}\right)\right]}{\pi \alpha \beta^{2}\left[1+\alpha^{\prime}\left(1-\pi^{\prime}\right)\left(1+d^{\prime}\right) /\left(1-d^{\prime}\right)\right]}
\end{gathered}
$$

where the primed quantities correspond to future and are unknown, $\pi\left(p_{01} /\left(1+p_{01}-p_{11}\right)\right.$ represents the unconditional probability of wet days and $d\left(p_{01}-p_{11}\right)$, a parameter that reflects the strength of the persistence (Katz, 1985). $p_{01}$ and $p_{11}$ represent the probability of wet day following dry day and wet day following wet day. Moreover, $\mu$ and $\sigma$ are the seasonal mean and variance of precipitation.

WGEN has four parameters that need to be adjusted to a changing climate, that is, four constraints are required. The probability distribution of seasonal mean values, $\Delta P$, is the only information available at present. Therefore, further three assumptions or constrains are required. Results from Waggoner (1989) that relate variability changes in climate change with the mean change were also used to constrain model parameters. Concerning the additional two constraints, one of the simplest approaches is to assume no changes in the nature of precipitation occurrence (i.e. $d^{\prime} / d=\pi^{\prime} / \pi=1$ ). Alternatively, additional constraints can be imposed based on the output from GCM or regional climate data. The latter approach is used in this study. Equation (3) shows the four constraints used,

$$
\begin{aligned}
\sigma^{\prime 2} / \sigma^{2} & =\left(\mu^{\prime} / \mu\right)^{1.31} ; \pi_{i}^{\prime} / \pi_{i}=a_{i}\left(\mu^{\prime} / \mu\right) ; d_{i}^{\prime} / d_{i} \\
& =b_{i}\left(\mu^{\prime} / \mu\right) ; i=1,12(\text { month })
\end{aligned}
$$

where the primed quantities correspond to the future and are unknown and coefficients $a$ and $b$ are the slope coefficients representing seasons.

For both methods, we then generated 100 realisations of future 30-year (2070-2099) daily precipitation data on the basis of 100 different samples collected from the probability distribution of seasonal mean precipitation change. Subsequently, the parameters for each realisation were adapted for the future using Equations 1-3. Although a larger number of samples is desired, only a small number (i.e. 100) of climate scenarios were sampled because of the computational costs involved in propagating the climate scenarios through several parametrically and structurally different hydrological models (discussed later). Therefore, to increase precision, disproportionate stratified sampling was adopted by dividing the population of sampling units into five population strata (i.e. minimum, Q1, median, Q3 and maximum) and subsequently sampling a fraction of the total sample randomly from each strata in proportion to the area enclosed by the probability function within each stratum.

The probabilistic scenario of the mean seasonal precipitation change is used to generate daily climate scenarios for each of the four catchments considered. Table II shows the minimum, maximum, median, 1st quartile (Q1) and 3rd quartile (Q3) that characterise the probability distribution of seasonal mean precipitation change $(\%)$ for the selected stations for both the SDprob and CF methods. Although an increase in precipitation for 2080s is observed for all the four quartiles and for all catchments, changes are largest in the Boyne and Backwater catchments. Mean precipitation change for the Irish grid using the $\mathrm{CF}$ method indicates that the 
Table II. Seasonal mean precipitation change (\%) for the period 2070-2099 for synoptic stations located at Cork airport, Mullingar, Belmullet, Claremorris and for the Grid representing republic of Ireland

\begin{tabular}{|c|c|c|c|c|c|c|c|}
\hline \multirow[b]{2}{*}{ Scenario no. } & \multirow[b]{2}{*}{ Basin } & \multicolumn{5}{|c|}{ Seasonal mean precipitation change $(\%)$} & \multirow[b]{2}{*}{ Maximum } \\
\hline & & Season & Minimum & Q1 & Median & Q3 & \\
\hline \multirow[t]{4}{*}{1} & \multirow[t]{4}{*}{ Blackwater (Stn: Cork A.) } & DJF & -0.706 & 1.863 & 4.189 & 6.587 & 15.008 \\
\hline & & MAM & -14.563 & -5.756 & -2.364 & 1.041 & 7.049 \\
\hline & & JJA & -27.245 & -13.554 & -10.118 & -6.925 & -1.295 \\
\hline & & SON & -22.209 & -10.994 & -8.108 & -5.472 & -1.084 \\
\hline \multirow[t]{4}{*}{2} & \multirow[t]{4}{*}{ Boyne (Stn: Mullingar) } & DJF & 2.278 & 10.366 & 12.407 & 14.72 & 26.898 \\
\hline & & MAM & -30.278 & -12.897 & -6.765 & -0.668 & 8.338 \\
\hline & & JJA & -29.423 & -15.393 & -12.555 & -10.061 & -2.301 \\
\hline & & SON & 0.341 & 2.736 & 4.4 & 6.149 & 13.161 \\
\hline \multirow[t]{4}{*}{3} & \multirow[t]{4}{*}{ Moy (Stn: Belmullet) } & DJF & -3.012 & -0.25 & 1.432 & 3.135 & 8.109 \\
\hline & & MAM & -22.45 & -9.303 & -4.5 & 0.286 & 7.936 \\
\hline & & JJA & -15.869 & -8.204 & -6.57 & -5.125 & -1.184 \\
\hline & & SON & -9.759 & -4.463 & -2.923 & -1.456 & 0 \\
\hline \multirow[t]{4}{*}{4} & \multirow[t]{4}{*}{ Suck (Stn: Claremorris) } & DJF & 2.278 & 10.366 & 12.407 & 14.72 & 26.898 \\
\hline & & MAM & -30.278 & -12.897 & -6.765 & -0.668 & 8.338 \\
\hline & & JJA & -29.423 & -15.393 & -12.555 & -10.061 & -2.301 \\
\hline & & SON & 0.341 & 2.736 & 4.4 & 6.149 & 13.161 \\
\hline \multirow[t]{4}{*}{5} & \multirow[t]{4}{*}{17 GCM (A2) } & DJF & -2.134 & 11.488 & 16.133 & 21.158 & 29.381 \\
\hline & & MAM & -16.035 & -7.088 & 0.327 & 14.442 & 25.550 \\
\hline & & JJA & -44.989 & -35.605 & -19.697 & -7.834 & 10.252 \\
\hline & & SON & -15.734 & -5.407 & -0.181 & 5.904 & 15.645 \\
\hline
\end{tabular}

Also shown are values for minimum, maximum, median and quartiles (Q1, 1st quartile; Q3, 3rd quartile; following Fealy, 2010).

amplitude of change is larger in comparison with the SDprob approach of Fealy (2010).

In applying WGEN, samples of changes in precipitation (\%) are randomly drawn from its probability distribution for each season and for both the SDprob and the $\mathrm{CF}$ approach, as characterised by values listed in Table I. The parameters of WGEN are then adjusted in proportion to the precipitation change (\%) using the functional relationship derived between the parameters of the weather generator and the mean precipitation. Consequently, 100 climate scenarios are generated for the 2070-2099 period for each of the catchments. Because daily precipitation at local scales is the primary input for rainfall-runoff models and plays an important role in the assessment of impacts of climate change on hydrologic response, this study only presents results for the generation of precipitation time series. The results section also compares the synthetic WGEN rainfall data with the deterministic regional climate scenarios available for Ireland from Fealy and Sweeney $(2007,2008)$.

\section{Hydrological modelling}

In hydrological modelling, uncertainty stems from a variety of sources including; data uncertainty, parameter uncertainty, model structural uncertainty and state uncertainty. Despite their acknowledged limitations, conceptual rainfall runoff models continue to be widely used for assessing the impacts of climate change on water resources and for projecting potential ranges of future impacts. The uncertainties associated with hydrological models have traditionally been given less attention in impact assessments until relatively recently. Therefore, in this study the uncertainty in the selection of hydrological models along with parameter uncertainty is accounted for by using several plausible conceptual model structures and their behavioural model parameters.

From among the large number of models that can be used for the purpose of modelling flow in catchments, we selected four conceptual rainfall runoff models: HyMOD (see Wagener et al., 2001), NAM (see Madsen, 2000), TANK (Sugawara, 1995) and TOPMODEL (Beven et al., 1995). Each of these models varies in the way they conceptualise the key hydrological processes and in complexity, primarily related to the number of parameters requiring calibration. Among the four selected models, NAM and TANK describe the behaviour of each component of the hydrological cycle at the catchment level by using a group of conceptual elements. TOPMODEL and HYMOD are both variable-contributing area models. In TOPMODEL, the spatial variability is taken into account through indices derived from topography whereas in HYMOD, the model spatial variability within basin is modelled using a probability distribution function. All four models use a single linear reservoir to model groundwater, and all models have been applied in numerous applications and their potential for application to simulate flow under changed climate has been discussed previously (e.g. Tanakamaru and Kadoya, 1993; Dietterick et al., 1999; Andersen et al., 2006; Najafi et al., 2010). The models used are independently developed by different researchers and organisations. The common assumption implicit in the application of conceptual models for climate change impact assessment is that the conceptual basis of the model enables the hydrological processes to realistically respond to changes in climatic input. 
The behavioural set of model parameters for each of the models and catchments used in this study were taken from Bastola et al. (2011). The authors used the period from 1971 to 1990 for model calibration and from 1991 to 2000 for model validation. A common assumption implicit in most of climate change impact studies is that hydrological models calibrated over the historical period are valid for use in the future under a changed climatic regime. However, only a small number of studies have tested the validity of this assumption. Arnell (1993) recommends that if model parameters are calibrated against a long time series of historical data containing both wet and dry periods, then these parameters can be assumed to be valid under future climates, with a greater degree of confidence. Similarly, Vaze et al. (2011) assessed the validity of rainfall-runoff models for use in climate change studies using the modelling result from four models on 61 catchments located within Australia. The authors infer that when the model is calibrated using more than 20 years of data, it can generally be used for climate impact studies where the future mean annual rainfall is not more than $15 \%$ drier or $20 \%$ wetter than the mean annual rainfall in the model calibration period. For the Irish basins, selected for this study, the annual change in precipitation is mostly within $\pm 10 \%$ change. As the calibration period as selected by Bastola et al. (2011) is sufficiently long to cover both wet and dry periods, that is, the 1970s is a relatively dry decade whereas the 1980 s are relatively wet, and the change in annual precipitation change compared with data that are used during model calibration is within $10 \%$. It is assumed that the calibrated parameters are valid for future simulation.

The probabilistic climate scenarios, outlined previously, are then propagated through the hydrological models. The method differs from the conventional multi-model ensemble approach mainly in two aspects. First, the conventional approach does not associate the likelihoods with different scenarios as it assumes all scenarios to be equally plausible. Second, the conventional approach is limited by the lack of availability of regional data corresponding to more extreme scenarios because no climate modelling centre has performed GCM simulations for more than a few emission scenarios. The use of probabilistic seasonal mean climate scenarios along with WGEN can help address this limitation. In this approach, the resulting distribution of precipitation change attempts to account for the uncertainties in the emissions scenarios and climate sensitivity, as it was estimated taking into account four marker SRES emission scenarios, GCM sensitivity and regional response.

In this study, land use changes are not considered separately, as the conceptual hydrological models used in this study do not directly use the information relevant to land use change. Therefore, the role of land cover is not explicitly included. Land cover plays a key role in controlling the hydrologic response of watersheds by changing evapotranspiration rates, soil moisture content and infiltration capacity, recharge and runoff. Furthermore, land use change and climate change form a complex and interactive system that interacts differently at different spatial and temporal scales. It has direct implication on the way catchment response to input and consequently on the simulation of future responses.

\section{Generalised Likelihood Uncertainty Estimation} methodology. The Generalised Likelihood Uncertainty Estimation (GLUE) developed by Beven and Binley (1992) is used to quantify the modelling uncertainties. The GLUE method is based on the premise that for a physically based hydrological model, no single optimum parameter set exists; rather, a range of different sets of model parameter values may represent the process equally well. Beven (2006) thoroughly reviews the equifinality problem for hydrology and related disciplines. Different model structures as well as different parameter sets in a particular model structure can be easily combined within this framework. In GLUE, a desired number of behavioural predictions from the four selected hydrological models are ranked and likelihood weighted to characterise the parameter as well as structural uncertainty. Details of the GLUE methodology can be found in (Beven and Binley, 1992), whereas the application of GLUE to the above models can be found in Bastola et al. (2011).

Model outputs for each of the behavioural simulators were weighted on the basis of the likelihood value derived during model calibration. To derive weights for climate scenarios, the individual scenarios are selected from among the plausible scenarios with a probability proportional to the area enclosed by the probability function within each stratum. This is done by multiplying the likelihood functions of the behavioural simulators and then rescaling it, similar to a probability measure, to make the cumulative sum equal to 1 .

\section{RESULTS}

\section{Deriving climate scenarios using WGEN}

The parameters of WGEN were estimated using meteorological data from the 14 synoptic stations spanning a 30 -year period. Figure 3 shows the spatial distribution of WGEN parameters (generated using the Spline function of ArcMap). Rainfall from stations in wet areas, such as western Ireland, is characterised as having higher values of alpha (shape parameter) as compared with the eastern region of Ireland. The southern part of Ireland shows the scale-dominated pattern in precipitation, that is, variable and more extreme rainfall. Similarly, the unconditional probability of wet days and the strength of persistence are higher in the wetter western region in comparison to the drier eastern region.

Figure 4, which compares the distribution of the observed and the WGEN generated precipitation (1961-1990) at the selected synoptic stations, shows that the distribution of observed and generated data for each of the 14 synoptic stations are linearly related. We compared 15 indices from the Statistical and Regional 

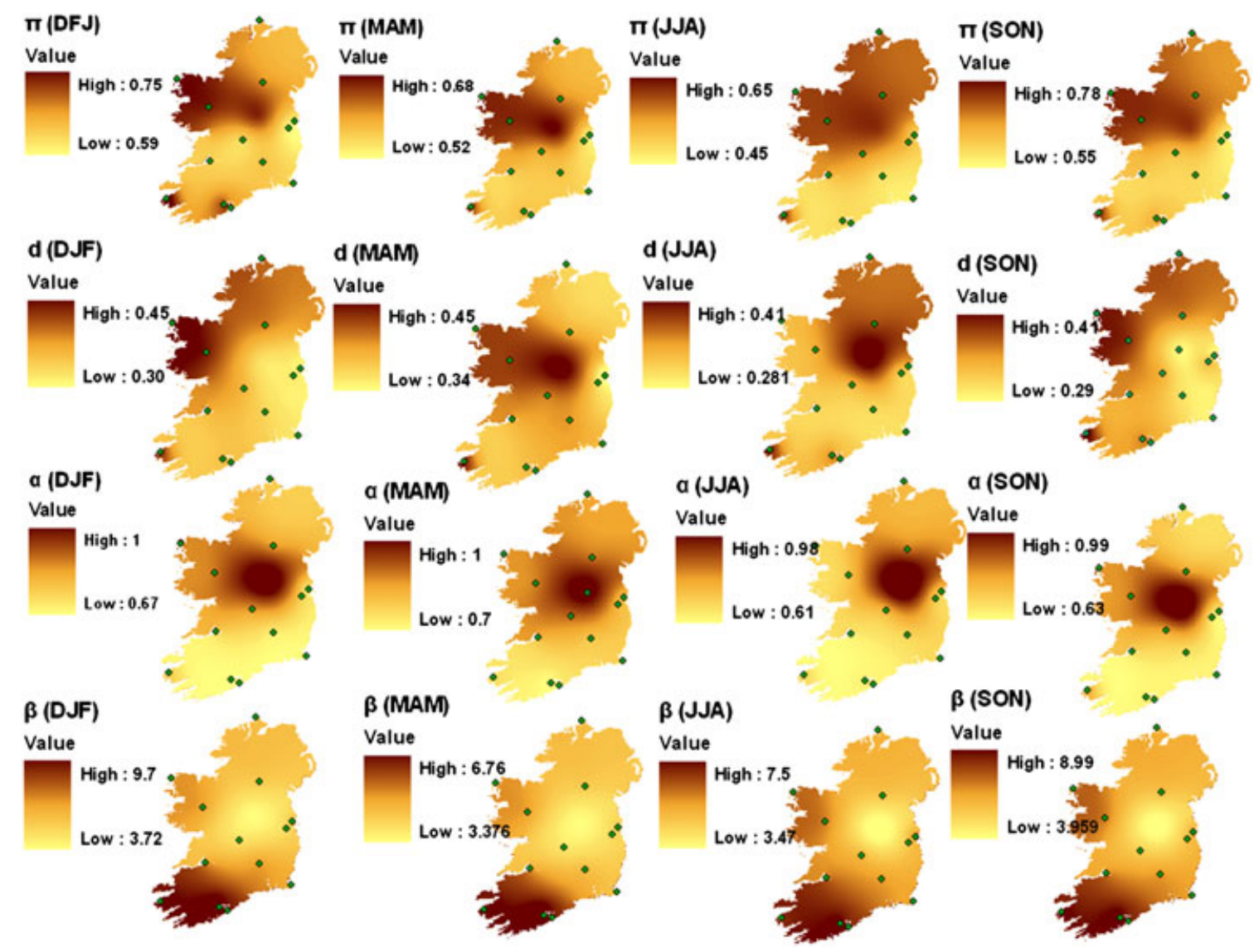

Figure 3. Spatial variation of the unconditional probability of wet days $(\pi)$, dependence parameter showing the persistence $(d)$ and parameter of rainfall amount model (i.e. $\alpha$ and $\beta$ ). The parameters are estimated using the 30-year daily observed data for 14 synoptic stations

dynamical Downscaling of Extremes for European Region (STARDEX) project, namely, mean climatological precipitation (mm/day) (pav); 20th, 50th and 90th percentile of rain day amounts (mm/day) (pq20, pq50 and pq90); number of days with precipitation greater than 10 mm (pn10); maximum consecutive dry days (pxcdd); mean wet day/dry day persistence (ppww/ppdd); mean, median and standard deviation of dry spell length in days (pdsav, pdsmed and pdssdv); and the greatest 3, 510 day total rainfall (px3d/px5d/px10d) and simple daily intensity (pint) to evaluate the generated time series. Figure 5

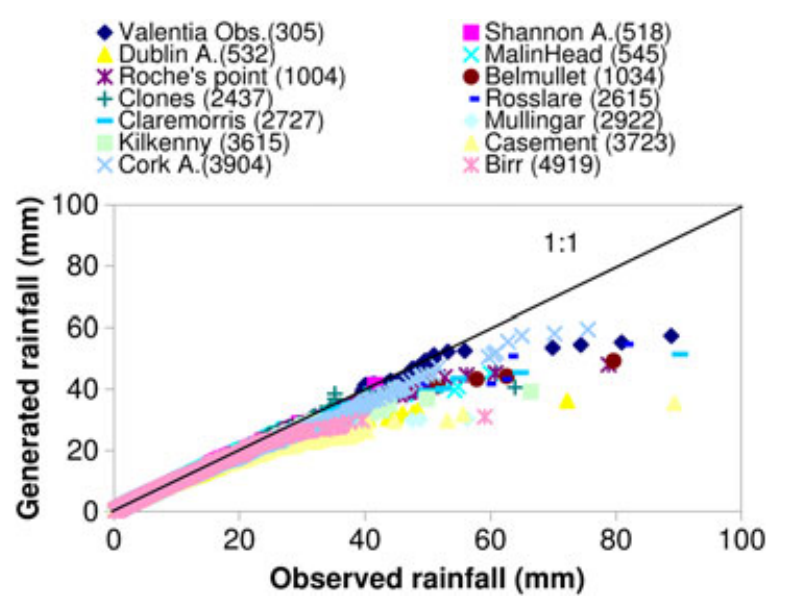

Figure 4. Scatter plot showing the comparison of observed against generated precipitation (sorted values) for 14 synoptic stations reveals that average pav, pint, ppww, pwsav, px3d and px10d for both observed and generated series are in close agreement for 14 synoptic stations. Some of the characteristics are not well reproduced by the model; specifically, the model showed the tendency to underestimate the mean dry day persistence, mean dry spell lengths and maximum number of consecutive dry days. As expected, the first-order Markov model used in WGEN seems poor in capturing these long timescale characteristics. Conditioning variables incorporating longer time memory of rainfall series as suggested by Harrold et al. (2003) would likely improve this; however, the additional complexity of such models was not considered to be of benefit to the present study.

Functional relationships between the parameters of WGEN and GCM output were sought to adapt the parameters of WGEN for future climatic conditions. The changes in parameters $\pi$ and $d$ are estimated from the relationship derived from the CF of $\pi$ and $d$ using the statistically downscaled regional scenarios obtained from HADCM3, CCCMA and CSIRO under the A2 scenarios (see Figure 6). Figure 6 shows the relationship between the change in mean precipitation and the mean change in $\pi$. As the relationship shows a strong linear trend for HADCM3, the functional form derived from HADCM3 for each of the four seasons are selected to constrain future changes in the probability of wet days (Figure 7). The value of this coefficient for the four seasons 


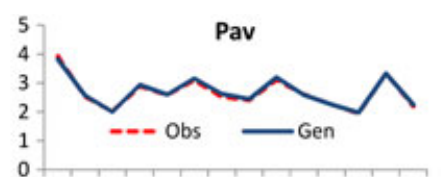

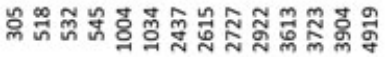
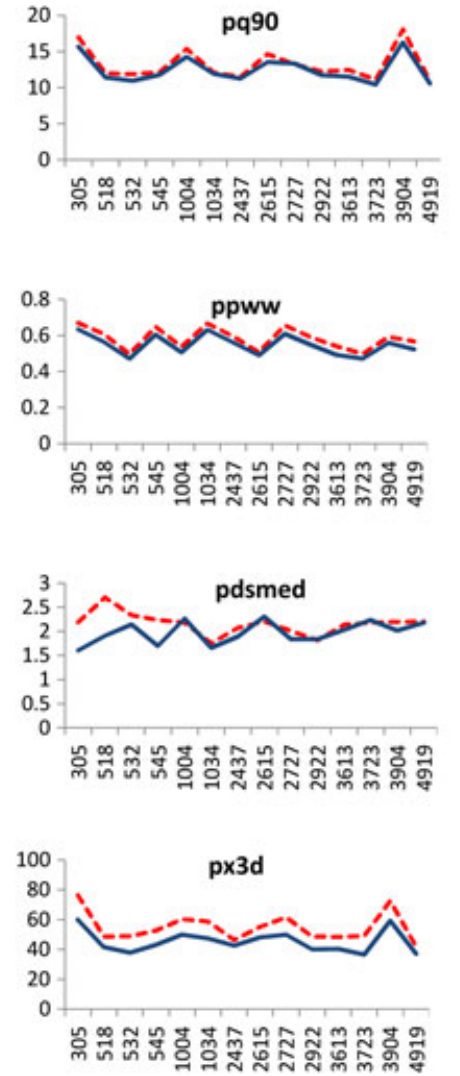
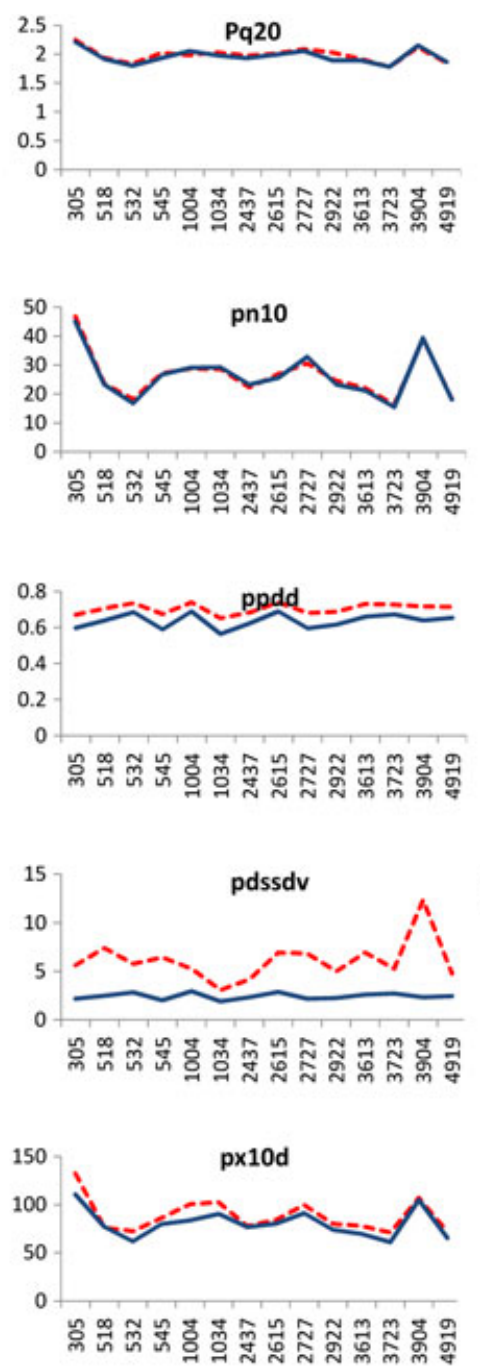
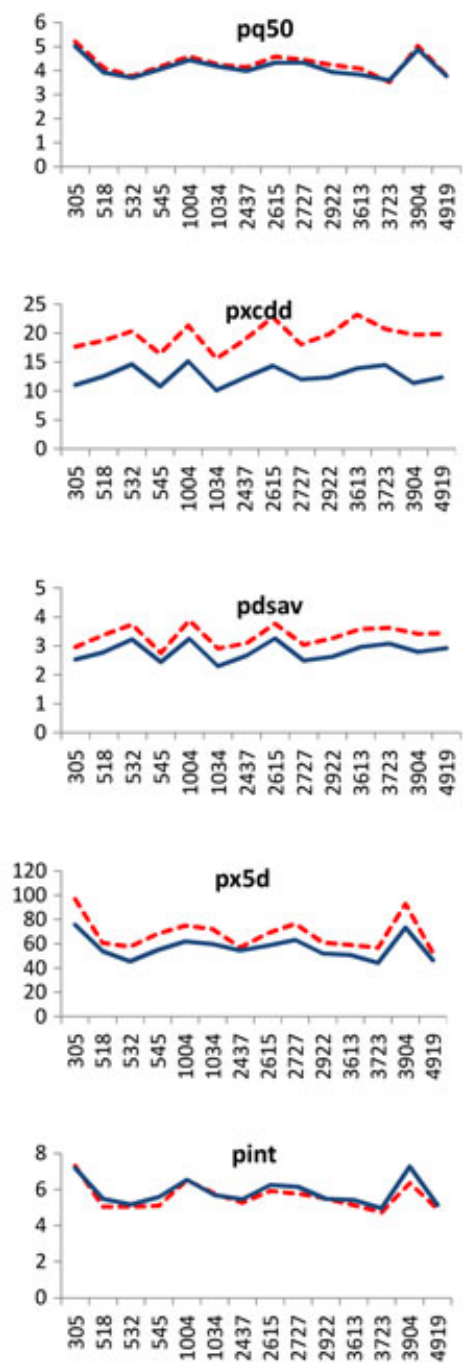

Figure 5. Comparison of the synthetically generated and observed daily rainfall using indices from STARDEX, namely, mean climatological precipitation (mm/day) (pav); 20th, 50th and 90th percentile of rain day amounts (mm/day) (pq20, pq50 and pq90); number of days with precipitation greater than $10 \mathrm{~mm}$ (pn10); maximum consecutive dry days (pxcdd); mean wet day/dry day persistence (ppww/ppdd); mean, median and standard deviation of dry spell length in days (pdsav, pdsmed and pdssdv); and the greatest 3,5 10 day total rainfall (px3d/px5d/px10d) and simple daily intensity (pint) to evaluate the generated time series. Shown are the indices averaged over the time period

December-February (DJF), March-May (MAM), JuneAugust (JJA) and September-November (SON) was estimated as 1.0032, 0.9961, 1.0056 and 0.99, respectively. The sampling of the three regression equations was not carried out because of the associated computational demand. No apparent relationship was observed between the parameter $d$ and the mean change in precipitation extracted from the six regional climate change scenarios for Ireland (data not shown). Therefore, it was assumed that $d$ will remain constant in the future.

Figure 8 shows the comparison of metrics defining the characteristics of the synthetic future rainfall data generated with the modified parameters of WGEN with the statistically downscaled regional climate scenarios, derived from HADCM3, CCCMA and CSIRO and forced with A2 SRES scenarios. Figure 8 shows that average pav, pq20 and pq50 are in close agreement for all stations and GCMs. As identified previously with the observations, some of the characteristics are not well reproduced; specifically, the model showed the tendency to underestimate the mean dry day persistence, the mean dry spell lengths and the maximum number of consecutive dry days.

\section{Hydrological impact of climate change scenarios}

Climate change scenarios derived from both the SDprob and the CF method are then used to force each of the four hydrological models to evaluate the impacts of potential climate change on water resources (Figure 2). The behavioural set of model parameters for each of the models and catchments used in this study were taken from Bastola et al. (2011). WGEN is capable of generating large sets of statistically consistent time series. Therefore, the catchment scale hydrological responses derived from these climate scenarios will show varying responses depending on the climate elasticity of a catchment, that is, a catchment with high variability in discharge and a low runoff coefficient is likely to be more sensitive to changes in precipitation than a catchment with low variability in discharge and higher runoff coefficient (e.g. Nemec and Schaake, 1982). 


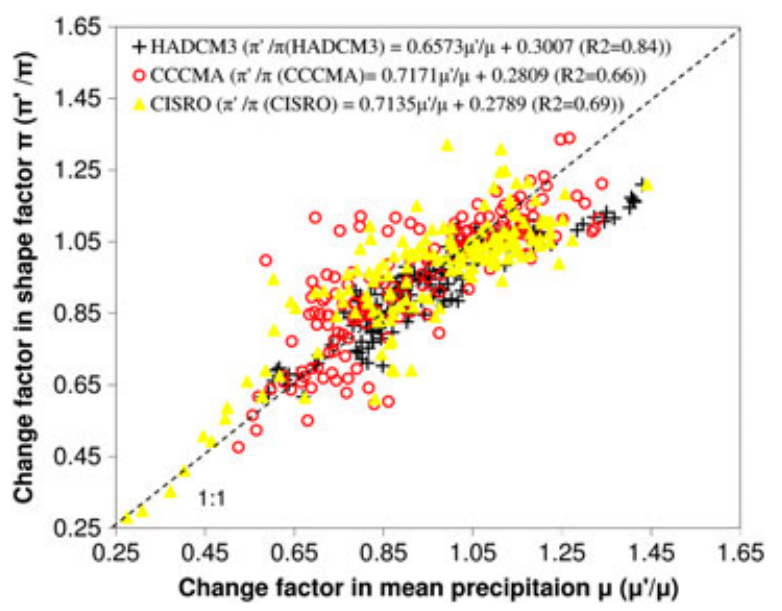

Figure 6. Relationship between the $\mathrm{CF}$ in mean precipitation $(\mu)$ and unconditional probability of wet days $(\pi)$ derived for the control period (1961-1990) and future data using HADCM3, CCMA and CSIRO under the A2 emission scenario. The primed and unprimed quantities correspond to the future and present period, respectively

Therefore, before using the scenarios to simulate future hydrological response under changed climatic conditions, it is essential to understand the uncertainties in hydrological response associated using generated climate data. For this purpose, the regional scenarios obtained from WGEN for the control period (1971-1990) were propagated through the hydrological models (also called Climvar). For the control period, the magnitude of uncertainty in prediction for each of the six scenarios is in the same order of magnitude derived during model calibration (Figure 9). Although the orders of magnitude are the same for all of the six statistically downscaled regional scenarios, the flows simulated from each of the GCMs under the A2 and B2 scenarios are different.
Consequently, uncertainties in prediction tend to increase when the six statistically downscaled scenarios are used (called SD). This increase in the uncertainty of the hydrological response, which varied among basins, can be attributed to the variability within the scenarios and differences in the climate elasticity among basins. Figure 9 shows that the magnitude of uncertainty for the control period is much greater when the WGEN scenarios (i.e. Climvar) are propagated through the hydrological models. This high value with respect to SD can be attributed to climate variability that is taken into account using 100 different scenarios and to the parameterisation and the structure of the WGEN model. As a result, the hydrological response simulated for the future period is also likely to show a larger range when these probabilistic-based scenarios are used.

Block resampling with replacement was also used to quantify the impact of natural climate variability. The method uses the resampling procedure that randomly selects 3-month blocks (consecutive months representing each season) from the original series to create a new series the same length as the original. The uncertainty in the streamflow associated with natural variability in streamflow is also shown in Figure 9 (called NATVAR). In comparison with the uncertainty associated with calibration, there is an increase in the uncertainty with the addition of climate scenarios from WGEN because these incorporate some element of natural variability. As can be seen in Figure 9, in comparison to other sources, natural variability is significantly high.

For the future period, the prediction uncertainty associated with both the SDprob and the CF method scenarios is very similar for all basins. However, it varies among basins. The runoff coefficient for the Boyne and
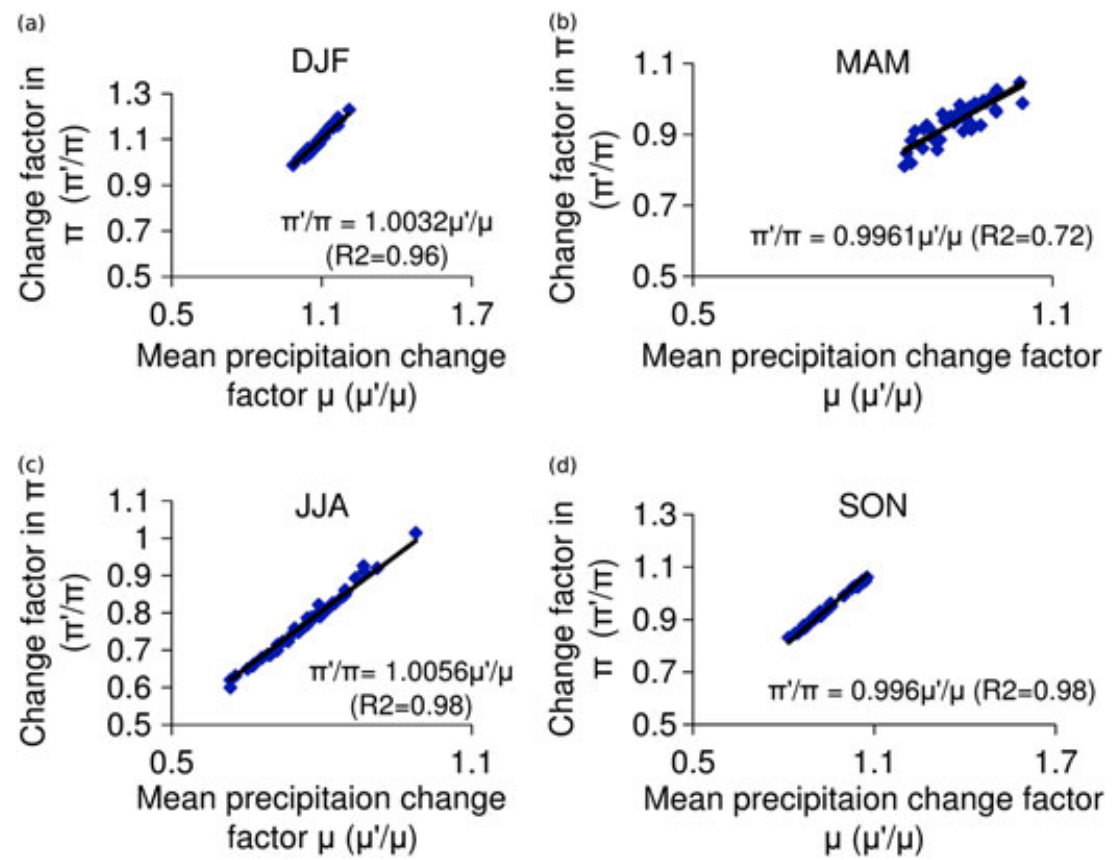

Figure 7. Scatter plot showing the CF in seasonal mean precipitation $(\mu)$ and unconditional probability of wet days $(\pi)$ derived from the control period (1961-1990) and future data using HadCM3 under A2 scenarios. The primed and unprimed quantity corresponds to the future and present period, respectively 

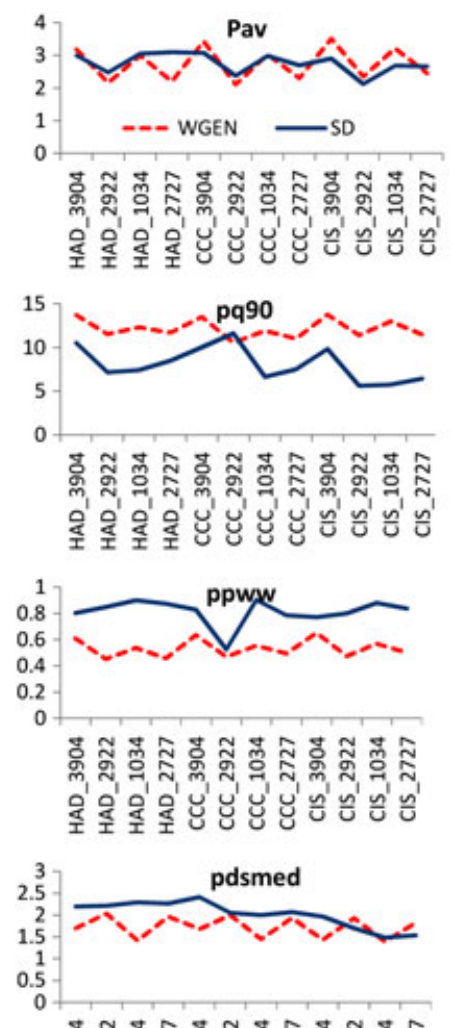

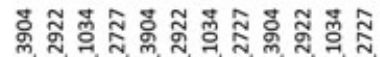

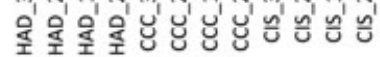

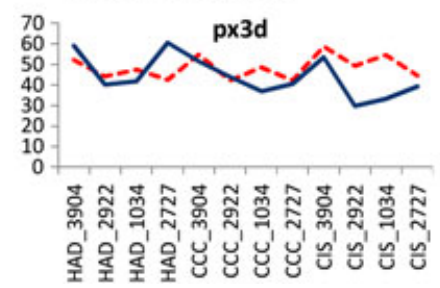

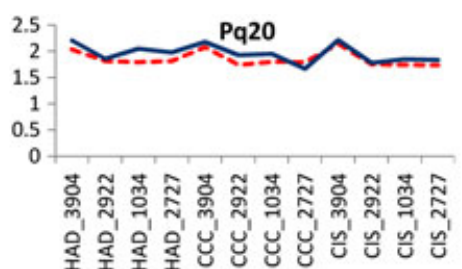
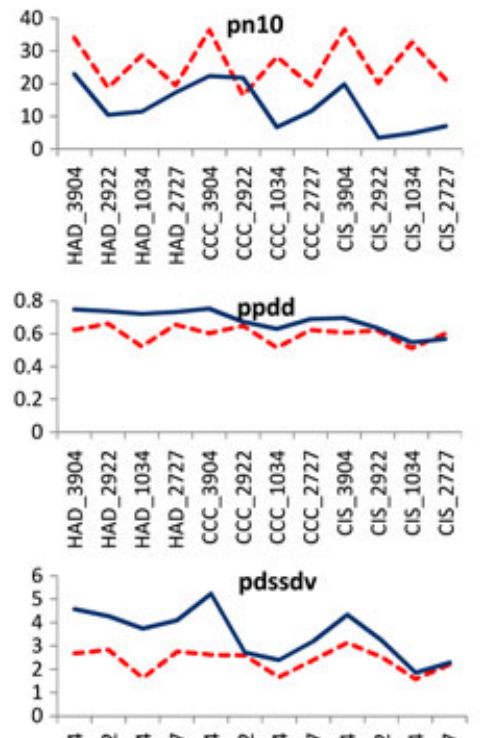

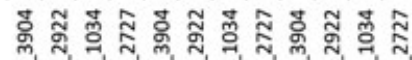
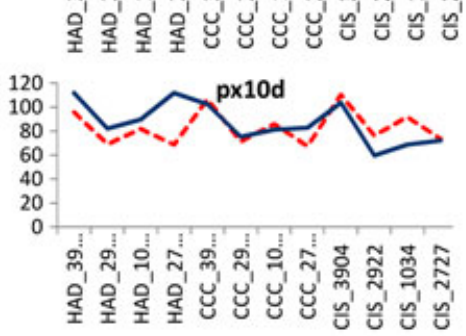
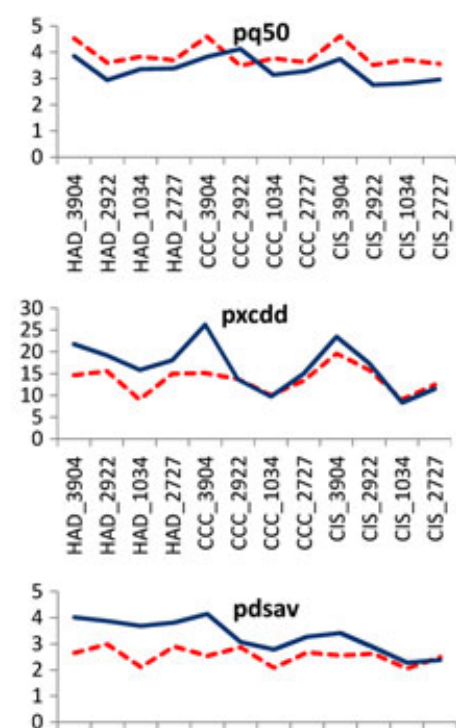

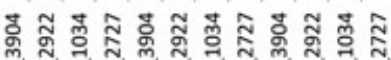
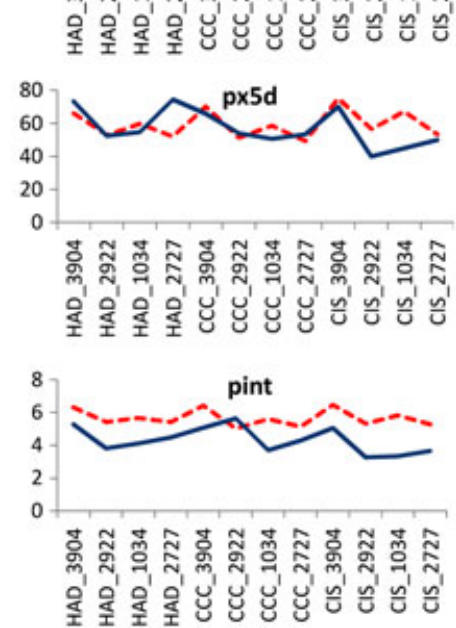

Figure 8. Comparison of the synthetically generated and statistically downscaled data derived from HADCM3, CCCMA and CISRO model for the $2080 \mathrm{~s}$. Shown are the indices originated from STARDEX, namely, mean climatological precipitation (mm/day) (pav), 20th, 50th and 90th percentile of rain day amounts (mm/day) (pq20, pq50 and pq90); number of days with precipitation greater than $10 \mathrm{~mm}$ (pn10); maximum consecutive dry days (pxcdd); mean wet day/dry day persistence (ppww/ppdd); mean, median and standard deviation of dry spell length in days (pdsav, pdsmed and pdssdv); and the greatest 3,510 day total rainfall $(\mathrm{px} 3 \mathrm{~d} / \mathrm{px} 5 \mathrm{~d} / \mathrm{px} 10 \mathrm{~d})$ and simple daily intensity (pint) to evaluate the generated time series

Suck is markedly lower than that in the Blackwater and Moy, and the nonlinear behaviours that are common in basins that have low runoff coefficients can be attributed to the larger prediction interval.

\section{Future hydrological response}

Figure 10 shows the median, upper $95 \%$ and lower 5\% seasonal flow on the basis of the time series calculated by both SDprob and CF method. Both the SDprob and the CF-based simulations use the same hydrological models and their behavioural set of model parameters estimated from the calibration data. The ranges of simulated flow derived with SDprob are in general smaller than the ranges estimated with the $\mathrm{CF}$ method in winter and larger in summer. This corresponds well to the differences observed in the probabilistic scenarios obtained from two methods (see Table I).

Figure 11 shows the PDFs for seasonal mean stream flow estimated for 2070-2099 using SDprob, CF method, SD and Climvar, derived from multiple realisation of scenarios from WGEN. The density is calculated on the basis of the proportion of daily future stream flow lying within the specified interval. In general, the shape of the PDFs for both SDprob and CF method is quite similar. In winter, PDFs are shifted to the right, indicating an increase winter flows. There is divergence between both approaches in spring for all catchments, with the WGEN scenarios displaying a decrease in spring flow and the CF method PDF displaying an increase. Summer and autumn mean flows also show a shift to the left. The large shift in the PDF in particular is likely due to the strong seasonal signal found using the $\mathrm{CF}$ simulated with 17 GCMs compared with the probabilistic approach discussed in this article.

\section{CONCLUSIONS}

The importance of probabilistic estimates of climate change impacts in policy formulation has been increasingly advocated by many researchers and policy makers. This study developed a probabilistic approach to simulate the 


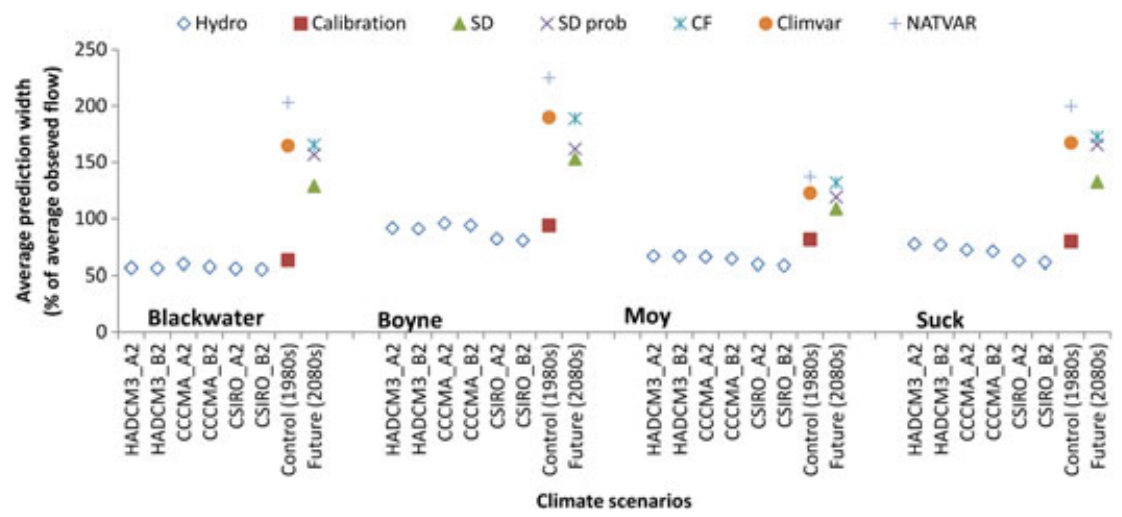

Figure 9. The uncertainty in prediction for the control (1980s) and future (2080s) arising from uncertainty in the hydrological models (Hydro), selection of scenario, hydrological models selection and GCM selection (SD); natural variability (NATVAR); and the multiple realisation of climate scenarios (Climvar) for control period. The magnitude of uncertainty obtained during model calibration (Calibration) is also shown for comparison. The uncertainty in model prediction using climate scenarios generated and adapted on the basis of probabilistic scenarios based on distribution of global mean temperature and regional scenarios (SDprob) and probabilistic scenarios constricted from 17 GCMs (CF) is also shown

hydrologic impact of climate change for selected Irish catchments by linking probabilistic climate scenarios with hydrological models. The probabilistic climate change scenarios (SDprob), representing four SRES scenarios, the range of climate sensitivity the and regional responses, were used along with a stochastic weather generator to construct the input for hydrological models. The approach was evaluated against probabilistic scenarios generated from 17 GCMs, used in model intercomparison projects, using a CF method for the Irish grid. The derived PDFs for seasonal mean flows using both approaches are somewhat similar. However, the ranges in simulated flow derived with the CF method are marginally larger than the same estimated with the SDprob because of the strong seasonal cycle in the CF estimated from the 17 GCMs. In both the SDprob and the CF approaches, the simulations for the 2080s in general showed a strong probability of decreases in summer flows in all catchments because the climate change projected mean winter flow for the 2080s is likely to increase.
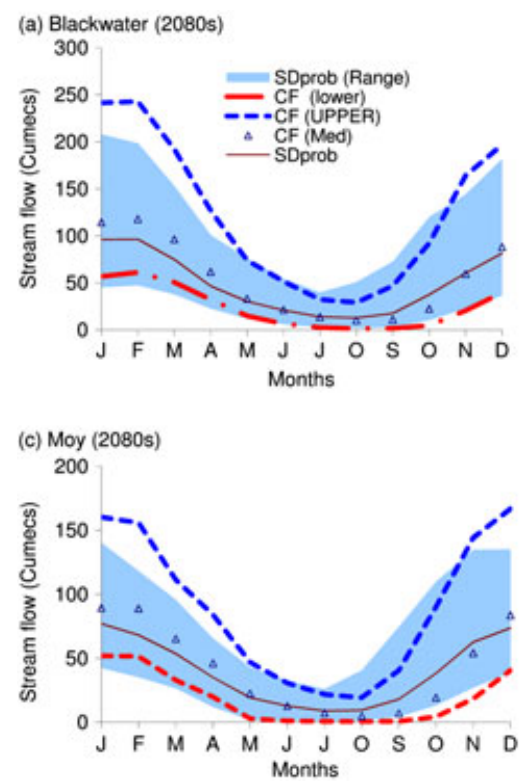

The results obtained are conditional on the assumptions made and the models used in constructing the probabilistic scenarios. The study is based on the assumption that the hydrological model parameters are time invariant, which may not hold true for future climate. Although this has been addressed using a long and climatically variable period for calibration and validation, the development of proper guiding rules for adapting hydrological model parameters for simulating future climate is required and needs further investigation. Moreover, daily climate change scenarios were generated by scaling the calibrated parameters of the weather generator in direct proportion to the changes sampled. Although a stochastic weather generator enables the efficient production of a large ensemble of scenarios for risk analysis, the method used to adapt these model parameters for future climate conditions is not well developed and requires strong assumption on the future sequence of wet and dry days to be made. Because of limited information on the structure of the future rainfall (b) Boyne (2080s)
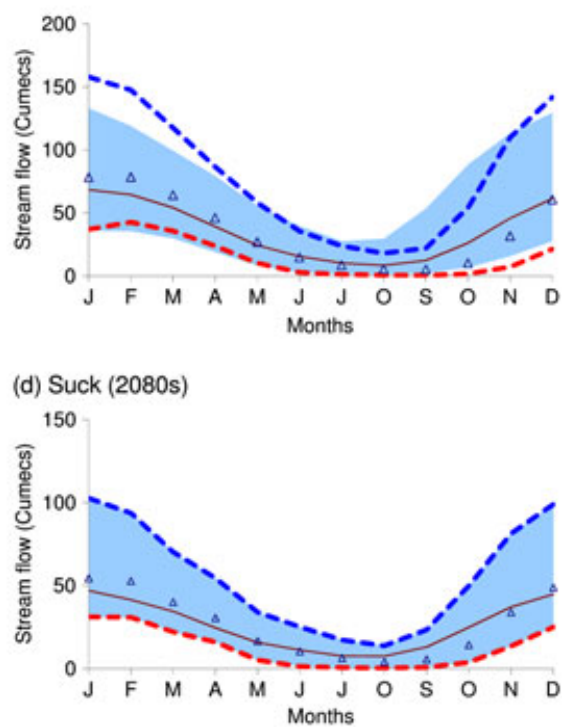

Figure 10. The $90 \% \mathrm{CI}$ of the seasonal prediction (2070-2099) simulated using the behavioural parameters of four hydrological models forced with daily probabilistic scenarios derived using SDprob and 17 GCMs (CF) 

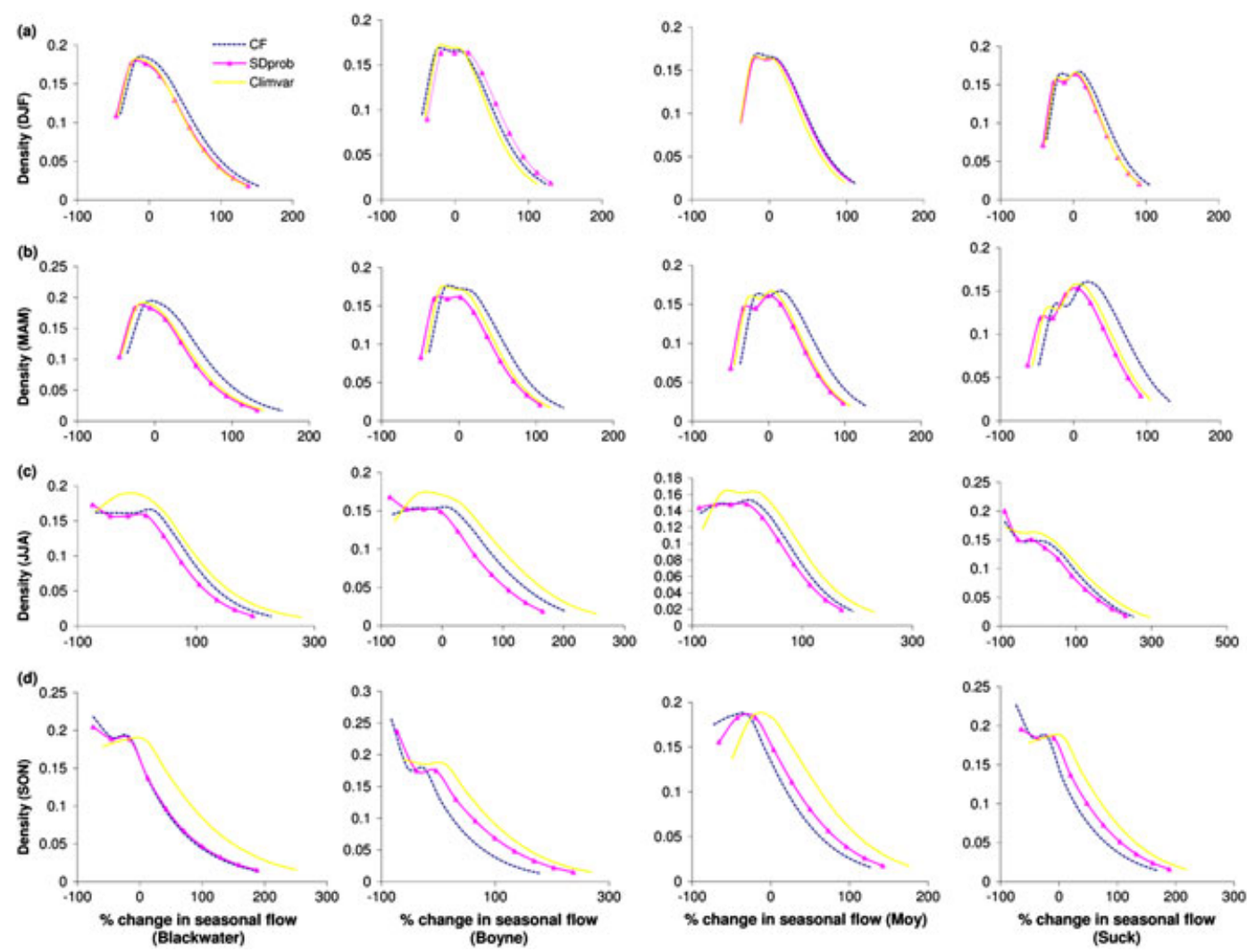

Figure 11. Probability distribution of mean seasonal stream flow in (a) Blackwater, (b) Boyne, (c) Moy and (d) Suck basin estimated using the behavioural parameters of four hydrological models forced with daily probabilistic scenarios derived using SDprob and 17 GCMs (CF)

patterns, a parsimonious model for rainfall was used. Because of scientific and modelling uncertainties, the availability of different statistical estimation approaches and the imprecise nature of information available for future climate, a unique probability distribution for streamflow is impossible. However, this study represents a first attempt at evaluating probabilistic hydrological impacts of climate change for Irish river catchments. Moreover, in contrast to the large number of studies that have generally disregarded the uncertainties in the representation of hydrological process used in hydrological models, this study focussed on future hydrologic impact by accounting for uncertainties in hydrological models along with uncertainties in regional climate change scenarios.

\section{ACKNOWLEDGEMENTS}

This work received financial support from Science Foundation Ireland's Research Frontiers Programme under the project title 'Quantifying the Cascade of Uncertainty in Climate Change Impacts for the Water Sector'. The quality of this article has been greatly improved by the thought full comments and suggestion from anonymous reviewers and editor assigned to handle this manuscript.

\section{REFERENCES}

Andersen HE, Kronvang B, Larsen SE, Hoffmann CC, Jensen TS, Rasmussen EK. 2006. Climate-change impacts on hydrology and nutrients in a Danish lowland river basin. Science of the Total Environment 365: 223-237.
Arnell NW. 1993. Hydrology and climate change. In The rivers handbook, vol. 2, Calow P, Petts GE (eds). 173-185.

Bastola S, Murphy C, Sweeney J. 2011. The role of hydrological modelling uncertainties in climate change impact assessments of Irish river catchments. Advances in Water Resources 34(5): 562-576. DOI: 10.1016/j.advwatres.2011.01.008.

Beven K. 2006. A manifesto for the equifinality thesis. Journal of Hydrology 320(1-2): 18-36.

Beven K, Binley AM. 1992. The future of distributed models: model calibration and uncertainty prediction. Hydrological Processes 6: 279-298.

Beven K, Lamb R, Quinn P, Romanowicz R, Freer J. 1995. TOPMODEL. In Computer Models of Watershed Hydrology, Singh VP (ed.). Water Resources Publications: Colorado; 627-668.

Cameron D. 2006. An application of the UKCIP02 climate change scenarios to flood estimation by continuous simulation for a gauged catchment in the northeast of Scotland, UK (with uncertainty). Journal of Hydrology 1-2: 212-226.

Caron A, Leconte R, Brissette F. 2008. An improved stochastic weather generator for hydrological impact studies. Canadian Water Resources Journal 33: 233-256.

Cloke HL, Jeffers C, Wetterhall F, Byrne T, Lowe J, Pappenberger F. 2010. Climate impacts on river flow: projections for the Medway catchment, UK, with UKCP09 and CATCHMOD. Hydrological Processes. DOI: 10.1002/hyp.7769.

Dietterick BC, Lynch JA, Corbett ES. 1999. A Calibration Procedure Using TOPMODEL to Determine Suitability for Evaluating Potential Climate Change Effects on Water Yield. Journal of the American Water Resources Association 35(2): 457-468.

Edwards PN. 2001. Representing the global atmosphere: computer models, data, and knowledge about climate change. In Changing the Atmosphere: Expert Knowledge and Environmental Governance, Miller CA, Edwards PN (eds). MIT Press: Cambridge, Massachusetts, USA; 31-65.

Fealy R. 2010. An Assessment of Uncertainties in Climate Modelling at the Regional Scale: The Development of Probabilistic Based Climate Scenarios for Ireland, STRIVE Report Series No. 48. Environmental Protection Agency, Co.: Wexford, pp. 1-66. ISBN 978-1-84095-345-9.

Fealy R, Sweeney J. 2007. Statistical downscaling of precipitation for a selection of sites in Ireland employing a generalised linear modelling approach. International Journal of Climatology 27(15): 2083-2094. 
Fealy R, Sweeney J. 2008. Statistical downscaling of temperature, radiation and potential evapotranspiration to produce a multiple GCM ensemble mean for a selection of sites in Ireland. Irish Geography 41(1): 1-27.

Fowler HJ, Blenkinsopa S, Tebaldi C. 2007. Review: Linking climate change modelling to impacts studies: Recent advances in downscaling techniques for hydrological modelling. International Journal of Climatology 27: 1547-1578.

Giorgi F, Mearns LO. 2003. Probability of regional climate change calculated using the reliability ensemble average (REA) method. Geophysical Research Letters 30: 1629-1632. DOI: 10.1029/ 2003GL017130.

Greene AM, Goddard L, Lall U. 2006. Probabilistic multimodel regional temperature change projections. Journal of Climate 19: 4326-4346.

Grubler A, Nakicenovic N. 2001. Identifying dangers in an uncertain climate. Nature 412, 15.

Gupta HV, Beven K, Wagener T. 2003. In Model calibration and uncertainty estimation, Anderson MG (ed.). John Wiley and Sons: Chichester, UK

Hall J, Murphy C. 2010a. Robust adaptation assessment- Climate change and the water supply sector. Climate2010- Climate Change and the Sustainable Management of Water Resources. http://www.climate2010. net/de/papers/1/119.

Hall J, Murphy C. 2010b. Vulnerability analysis of future public water supply under changing climate conditions: A study of the Moy catchment, western Ireland. Water Resources Management 24(13): 3527-3545.

Hargreaves GL, Hargreaves GH, Riley JP. 1985. Irrigation water requirement for Senegal River Basin. Journal of Irrigation and Drainage Engineering, ASCE 111(3):265-275.

Harrold TI, Sharma A, Sheather SJ. 2003. A nonparametric model for stochastic generation of daily rainfall amounts. Water Resources Research 39(12): 1300. DOI: 10.1029/2003WR002570.

Horton P, Schaefli B, Mezghani A, Hingray B, Musy A. 2006. Assessment of climate-change impacts on alpine discharge regimes with climate model uncertainty. Hydrological Processes 20: 2091-2109.

Hutchinson MF. 1991. Climatic analysis in data sparse regions. In Climatic risk in crop production: models and measurement for the semiarid tropics and arid subtropics, Muchow RC, Bellamy JA (eds). CAB International: Wallingford; 55-73.

IPCC. 2007. Cimate Change 2007. In The Physical Science Basis. Contribution of Working Group I to the Fourth Assessment Report of the Intergovernmental Panel on Climate Change, Solomon S, Qin D, Manning M, Chen Z, Marquis M, Averyt KB, Tignor M, Miller HL (eds). Cambridge University Press: Cambridge, UK.

Katz RW. 1985. Probabilistic models. In Probability, statistics, and decision making in the atmospheric sciences, Murphy AH, Katz RW (eds). Westview Press: Boulder, CO; 261-288.

Knutti R, Cermak J, Furrer R, Tebaldi C, Meehl G. 2010. Challenges in combining projections from multiple climate models. Journal of Climate 23: 2739-2758. DOI: 10.1175/2009JCLI3361.

Madsen H. 2000. Automatic calibration of a conceptual rainfall-runoff model using multiple objectives. Journal of Hydrology 235: 276-288.

Maraun D, Wetterhall F, Ireson AM, Chandler RE, Kendon EJ, Widmann M, Brienen S, Rust HW, Sauter T, Themeß1 M, Venema VKC, Chun KP, Goodess CM, Jones RG, Onof C, Vrac M, Thiele-Eich I. 2010. Precipitation downscaling under climate change: Recent developments to bridge the gap between dynamical models and the end user. Reviews of Geophysics 48: RG3003. DOI: 10.1029/2009RG000314.

Meehl GA, Covey C, Delworth T, Latif M, McAvaney B, Mitchell JFB, Stouffer RJ, Taylor KE. 2007. The WCRP CMIP3 multi-model dataset: A new era in climate change research. Bulletin of the American Meteorological Society 88: 1383-1394.

Min SK, Simonis D, Hense A. 2007. Probabilistic climate change predictions applying Bayesian model averaging. Philosophical Transactions of the Royal Socitey A 365: 2103-2116.

Mitchell JFB, Johns TC, Eagles M, Ingram WJ, Davis RA. 1999. Towards the construction of climate change scenarios. Climate Change 41: 547-581.

Mitchell TD. 2003. Pattern Scaling: An examination of the accuracy of the technique for describing future climates. Climate Change $\mathbf{6 0}$ : 217-242.

Mooney PA, Mulligan FJ, Fealy R. 2010. Comparison of ERA-40, ERAInterim and NCEP/NCAR reanalysis data with observed surface air temperatures over Ireland. International Journal of Climatology. DOI: 10.1002/joc.2098.

Murphy C, Charlton R. 2008. Climate Change and Water Resources in Ireland. In Climate Change: Refining the Impacts, Sweeney J. (ed.). Government Publications: Environmental Protection Agency, Johnstown Castle, Wexford.
Murphy JM, Sexton DMH, Barnett DN, Jones GS, Webb MJ, Collins M, Stainforth DA. 2004. Quantification of modelling uncertainties in a large ensemble of climate change simulations. Nature 430: 768-772. DOI: $10.1038 /$ nature02771.

Najafi MR, Moradkhani H, Jung WI. 2010. Combined Effect of Global Climate Projection and Hydrologic Model Uncertainties on the Future Changes of Streamflow. ASCE Conference Proceedings 371, 10. DOI: 10.1061/41114(371)10.

Nemec J, Schaake J. 1982. Sensitivity of water resource systems to climate variation. Hydrological Sciences Journal 27(3): 327-343.

New M. Hulme M. 2000. Representing uncertainties in climate change scenarios: a Monte Carlo approach. Integrated Assessment 1: 203-213.

New M, Lopez A, Dessai S, Wilby R. 2007. Challenges in using probabilistic climate change information for impact assessments: an example from the water sector. Philosophical Transactions of the Royal Society A: Mathematical, Physical and Engineering Sciences 365 (1857): 2117-2131.

Racsko P, Szeidl L, Semenov M. 1991. A serial approach to local stochastic weather models. Ecological Modelling 57: 27-41.

Richardson CW, Wright DA. 1984. WGEN: a model for generating daily weather variables. U.S. Dep. of Agric., Agric. Res. Service, ARS-8: Springfield, Virginia; 83.

Santer BD, Wigley TML, Schlesinger ME, Mitchell JFB. 1990. Developing Climate Scenarios from Equilibrium GCM results. Report No. 47, Max Planck-Institut-für-Meteorologie, Hamburg; 29.

Semenov MA, Barrow EM. 1997. Use of Stochastic Weather Generator in the Development of Climate Change Scenarios. Climatic Change 35: 397-414.

Semenov MA, Brooks RJ, Barrow EM, Richardson CW. 1998. Comparison of the WGEN and LARS-WG stochastic weather generators in diverse climates. Climate Research 10: 95-107.

Stainforth DA, Aina T, Christensen C, Collins M, Faull N, Frame DJ, Kettleborough JA, Knight S, Martin A, Murphy JM, Piani C, Sexton D, Smith LA, Spicer RA, Thorpe AJ, Allen MR. 2005. Uncertainty in predictions of the climate response to rising levels of greenhouse gases. Nature 433: 403-406.

Steele-Dunne S, Lynch P, McGrath R, Semmler T, Wang S, Hanafin J, Nolan P. 2008. The impacts of climate change on hydrology in Ireland. Journal of Hydrology 356: 28-45.

Sugawara M. 1995. Tank model. In Computer models of watershed hydrology, Singh VP (ed.). Water Resource Publication, Littleton, Co.: Colorado; 165-214.

Supit I. 1994. Global radiation. Publication EUR 15745 EN of the Office for Official Publications of the EU: Luxembourg.

Tanakamaru H, Kadoya M. 1993. Effects of climate change on the regional hydrological cycle of Japan. IAHS Publication no. 212: Wallingford, Oxfordshire; 535-542.

Tebaldi C, Smith RL, Nychka D, Mearns LO. 2005. Quantifying uncertainty in projections of regional climate change: a Bayesian approach to the analysis of multi-model ensembles. Journal of Climate 18: $1524-1540$.

Vaze J, Post DA, Chiew FHS, Perraud JM, Viney NR, Teng J. 2011. Climate nonstationarity-Validity of calibrated rainfall-runoff models for use in climate change studies. Journal of Hydrology 394(3-4): 447-457.

Wagener T, Boyle DP, Lees MJ, Wheater HS, Gupta HV, Sorooshian S. 2001. A framework for development and application of hydrological models. Hydrological and Earth System Sciences 5(1): 13-26.

Waggoner PE. 1989. Anticipating the Frequency Distributions of Precipitation if Climate Change Alters its Mean. Agriculture and Forest Meteorology 47: 321-337.

Wilby RL, Dessai S. 2010. Robust adaptation to climate change. Weather 65: 180-185. DOI: 10.1002/wea.543.

Wilby RL, Harris I. 2006. A framework for assessing uncertainties in climate change impacts: low flow scenarios for the River Thames, UK. Water Resources Research 42: W02419. DOI: 10.1029/2005WR004065.

Wilby RL, Hay LE, Gutowski WJ, Arritt RW, Takle ES, Pan Z, Leavesley GH, Clark MP. 2000. Hydrological responses to dynamically and statistically downscaled climate model output. Geophysical Research Letters 27: 1199-1202.

Wilby RL, Wigley TML. 1997. Downscaling general circulation model output: a review of methods and limitations. Progress in Physical Geography 21: 530-548.

Wilks DS. 1992. Adapting stochastic weather generation algorithms for climate changes studies. Climate Change 22: 67-84.

Wilks DS, Wilby RL. 1999. The Weather Generation Game: A Review of Stochastic Weather Models, Progress in Physical Geography 23(3): 329-357.

Xu CY, Singh VP. 2000. Evaluation and generalization of radiation based methods for calculating evaporation. Hydrological Processes 14: 339-3349. 